\title{
LEACHING TREATMENT METHOD OF PETROLEUM HYDROCARBON POLLUTION IN FARMING LAND FOR ECOLOGICAL PROTECTION IN CHINA
}

\author{
SHANG, Z. X. ${ }^{1,2}-$ ZHENG, X. L. ${ }^{1 *}-$ MA, Y. F. ${ }^{2}$ \\ ${ }^{1}$ College of Environmental Science and Engineering, Ocean University of China \\ Qingdao, Shandong Province, China \\ ${ }^{2}$ School of Resources and Environmental Engineering, Shandong University of Technology \\ Zibo, Shandong Province, China \\ (phone: +86-13964398213) \\ ${ }^{*}$ Corresponding author \\ e-mail: Understand27@163.com \\ (Received 21 ${ }^{\text {st }}$ Mar 2019; accepted 24 $4^{\text {th }}$ May 2019)
}

\begin{abstract}
Ectopic elution is a commonly used method for remediation of petroleum hydrocarbon contaminated soil. In the work, surfactant was used to wash petroleum hydrocarbon contaminated soil. Then, we investigated the effects of different surfactant combination ratio and concentration, the auxiliary concentration and temperature on the removal efficiency of petroleum hydrocarbon pollutants. The results showed that the oil solubilization capacity of Tw-80 was higher than that of SDS (Sodium dodecyl sulphate, SDS), and the removal rate of oil was the highest when the compound ratio of SDS/Tw-80 was $50-60$. With the increase of surfactant concentration and temperature, the oil removal rate increased. The increase of alkaline solution was in favour of heavy oil separation and removal of tricyclic aromatic compounds. Sodium chloride, calcium chloride and magnesium chloride reduced the removal rate of oil, while sodium sulfate, sodium bicarbonate, sodium bicarbonate, sodium silicate and sodium phosphate increased the removal rate of oil.
\end{abstract}

Keywords: ecological protection, petroleum hydrocarbon contaminated soil, surfactant, elution treatment, oil removal rate

\section{Introduction}

During the drilling, exploitation and transportation process of petroleum, the pollutants are released into the surrounding soil environment due to dropping and leaking, which changes the physical and chemical properties of soil. It is difficult to grow for Crops and surface vegetation, causing significant damage to the ecological environment. In particular, aromatic substances, which are more toxic to petroleum, can accumulate in crops and threaten human through the food chain (Kim et al., 2017). At present, soil excavation, soil steam extraction, extraction, bioremediation and elution are the main removal methods of petroleum hydrocarbons in soil (Åslund et al., 2013; Dong et al., 2015; Kim et al., 2017). Soil excavation is to excavate the contaminated soil and then cover with fresh, unpolluted soil. It is suitable for the small-scale polluted areas as well as the subsequent treatment of excavated soil. As people usually use incineration method, the cost of pollution treatment is very high. Soil steam extraction has a good effect on high vapor pressure compounds (e.g., hydrocarbons), rather than on non-volatile organic compounds such as polyaromatic hydrocarbons and polychlorinated biphenyls (PCBs) (Mota et al., 2015; Mauko et al., 2018).

Bioremediation is more challenging when petroleum is mixed with water. The easyto-degrade substance has good treatment effect, but the effect is not significant for the 
organic matter that is not easy to be biodegraded by oxygen. The leaching method includes the traditional pump extraction and the surface active agent solution leaching developed in recent years. Due to the low solubility of petroleum pollutants in water, the ideal effect cannot be achieved by the traditional pump leaching method with clean water.

In comparison, the heterotopic elution of surfactant has advantages, such as low energy consumption, small equipment investment, simple process, wide application range, fast speed and waste reduction. It has been widely studied in Europe, America and Japan, applied to remediation of organic matter, heavy metals and radioactive contaminated soil (Arauzo et al., 2015). However, the methods of surface active agent heterotopic elution for remediation of petroleum-contaminated soil are limited to laboratory research, large-scale and flexible soil elution equipment.

The work used an anionic-Nonionic surfactant to elute oil-contaminated soil, and investigated the effects of various operating conditions on the removal rate of petroleum as well as the mechanism of action. Some technical supports were provided for the remediation of petroleum contaminated soil with surfactant elution. This investigation, concerning the effect of solubilizing petroleum with single surfactant and compound surfactant, was to determine the necessary operating conditions of surfactant elution experiment by single factor experiment. Besides, we studied the influence factors of complex surfactant elution on remediation of petroleum contaminated soil, the samples before and after leaching by three-dimensional fluorescence spectroscopy, and the changes of petroleum components in the soil before and after treatment.

\section{Mechanism of action}

\section{Mechanism of synergism of surfactants}

\section{Subheading}

Surfactant (surface active agents) refers to a class of substances that can significantly reduce solvent surface tension and liquid-liquid interfacial tension. It has certain structure, hydrophilic and oil-friendly properties and special adsorption (Arauzo et al., 2015). When the concentration of surfactant in water is low, it exists in the form of monomer in water and adsorbs at the water-gas interface. The increase of its concentration in water leads to the increased adsorption of surfactant at the water-gas interface. As a result, the interfacial tension between water and gas decreases. The hydrophobic part of the surfactant molecule interacts with each other to form the association in the solution, namely the concentration of micelle (micelle). Surfactant forms a micelle in water, which is the CMC (critical micelle concentration). CMC is an important index to measure the properties of surfactants. In CMC, surfactant solutions have the lowest interfacial tension and can dissolve insoluble petroleum pollutants (Arauzo et al., 2015) (See Fig. 1).

At present, most researchers believe that surfactants remove petroleum pollutants from soil through the following mechanisms (Elazhari-Ali et al., 2013; Akinlua et al., 2015; Gao et al., 2016; Brown et al., 2017), curling (rollup) and solubilizing (solubilization). Generally, surfactants below or above CMC can improve the removal of petroleum pollutants in soil. Therefore, the mechanism of shrinkage and solubilization functions. 


\section{Surfactant solubilization mechanism}

Solubilization refers to the situation that the insoluble petroleum pollutants adsorbed by the soil are desorbed from the soil under the action of surfactants and distributed to the water phase. It depends on the formation of the insoluble organic pollutants in the micellar phase of the aqueous solution by the surfactants. Solubilization usually occurs above the critical micelle concentration due to a large number of surfactant micelles formed in aqueous solution (Jha et al., 2018).

There are lots of studies about the solubilisation of PAH (polycyclic aromatic hydrocarbon, PAH) and other insoluble organic pollutants by surfactants (Li et al., 2014; Yang et al., 2015; Janajreh et al., 2018). Edwards et al. focused on the solubilization of PAHs by Brij30, Igepal CA-720, Tergitol NP-10 and Triton X-100 (Mortazavi et al., 2013; Fallah et al., 2015). The concept of molar solubilization ratio (Molar Solubilization Ratio, MSR) is proposed to describe the solubilization of surfactant solution quantitatively, as shown in Eq.(1).

$$
M S R=\left(S-S_{c m c}\right) P\left(C_{s}-C_{m c m}\right)
$$

where $C_{s}$ and $C_{c m c}$ are the concentrations of surfactant solution greater than/equal to CMC, respectively; $S$ and $S_{c m c}$ in CMC are the apparent solubilities of organic matter when the surfactant concentrations are $C_{s}$ and $C_{c m c}$.

Another quantitative description of solubilization of surfactants is the partition coefficient $\left(K_{m c}\right)$ of micelle phase P-water phase, as shown in Eq.(2).

$$
K_{m c}=X_{m c} P X_{a}
$$

where $X_{m c}$ is the molar fraction of organic matter in the micellar phase, which can be calculated by using Eq.(3).

$$
X_{m c}=\left(S-S_{c m c}\right) P\left(C_{s}-C_{c m c}+S-S_{c m c}\right)
$$

Parameter $X_{a}$ is the molar fraction of organic matter in the aqueous phase. In dilute solution, $V_{w}$ is the molar volume of water $(0.101805 \mathrm{~L} / \mathrm{mol})$, so we can obtain Eq. (4).

$$
K_{m c}=5514 \operatorname{MSRP}\left[S_{c m c}(1+M S R)\right]
$$

\section{Experiment}

\section{Experimental materials}

According to the situation of China's Tarim oil and gas field and its surrounding areas, we considered the complex composition of drilling mud and the uneven distribution properties of surrounding desert sand, to make sure the representativeness of the collected mud and surrounding desert sand samples. In the $1 \mathrm{~m}^{2}$ sample plot the sample was evenly distributed and the water-based mud of 10 wells in the $1 \mathrm{~m}^{2}$ plot and the sand layer of $0-20 \mathrm{~cm}$ in the surrounding $10 \mathrm{~m}$ area were collected. A total of 12 water-based mud samples and sand analysis samples were collected. Mud samples were stored in cold storage until analysis, and confined storage reduced the volatilization and interference from the surrounding environment. The soil samples were processed within 
14 days of pre-treatment, and the extract analysis was completed within 40 days. After mixing the soils, dry naturally at room temperature, and remove the residual roots, plastics and other debris. Then, grind with a mortar, and sift over 100 meshes. Finally, store it in a brown wide-mouth bottle. Some physical and chemical properties of the soil are determined (See Table 1).

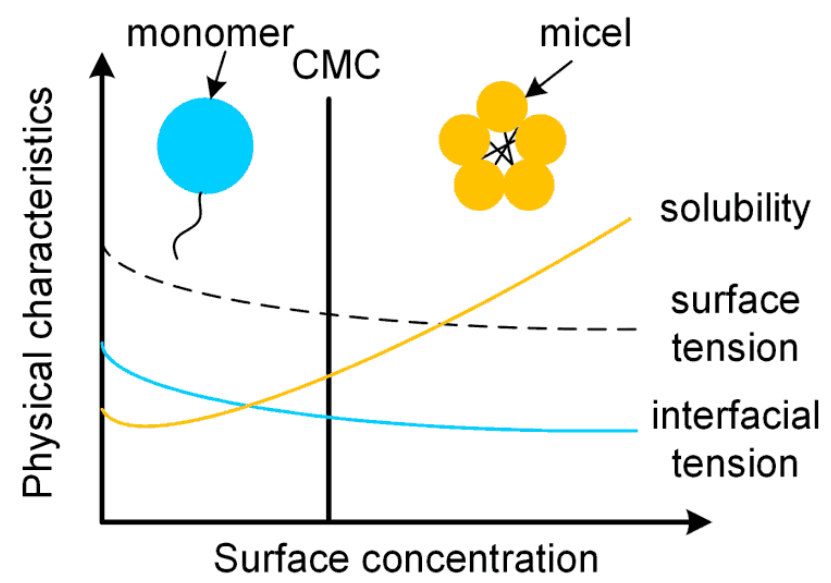

Figure 1. Surface tension, Interfacial tension and Pollutant Solubility changes with Surfactant concentration

Table 1. Physical and chemical parameters of soils used (TOC is the total organic carbon, and TPH is the total petroleum hydrocarbons in soil)

\begin{tabular}{c|c|c|c|c}
\hline $\mathbf{p H}$ & Rate of water content $(\%)$ & Salt content $(\%)$ & TOC $(\mathbf{g} / \mathbf{k g})$ & TPH $(\%)$ \\
\hline 7.41 & 1.09 & 0.43 & 3.21 & 0.05 \\
\hline
\end{tabular}

\section{Experimental content}

\section{Preparation of petroleum-contaminated soil samples}

At first, some crude oil was taken and dissolved by dichloromethane. Then, some spare soil was put into the beaker. The solid-liquid mixture was stirred by a glass rod. Finally, the solvent of the mixture was evaporated in the ventilating cabinet and simulated soil sample was obtained.

\section{Method for determination of petroleum in soil}

The concentration of petroleum in the solution was determined by ultraviolet spectrophotometry. Crude oil was used to prepare $1.0 \mathrm{~g} / \mathrm{L}$ standard solution with dichloromethane as solvent. The standard solution was diluted by UV spectrophotometer (HACH-DR6000), and scanned in the wavelength range of 200-400 nm.

Weigh $0.1 \mathrm{~g}$ of petroleum in a beaker, and dissolve it in dichloro-A hospital. Then, transfer it to $100 \mathrm{~mL}$ volume bottle and set volume. The standard oil storage solution concentration is $1,000 \mathrm{mg} / \mathrm{L}$. The solution was taken from $5 \mathrm{~mL}$ volume bottle to $25 \mathrm{~mL}$ volume bottle with the fixed volume. The oil concentration was $200 \mathrm{mg} / \mathrm{L} ; 0.4,0.8,1.2$, 1.6, 2 and $10 \mathrm{~mL}$ colorimetric tubes were removed, and the volume was fixed to the 
mark line. The standard solutions for this series of concentrations were $8,16,24,32$ and $40 \mathrm{mg} / \mathrm{L}$.

The oil contents of the eluted soil and the original soil were used to calculate the removal rate, as given by Eq.(5).

$$
R=\left[1-\frac{(A-B) * N * 25 * 100}{K * 1000 * 1000 * 2 w}\right] * 100 \%=\left[1-\frac{(A-B) * N}{800 K w}\right] * 100 \%
$$

where $R$ is the removal rate; $A$ the absorbance; $A=K \times B$ is the standard curve; $N$ the dilution multiple; $w$ the oil content of the oily soil sample.

\section{Solubilization test}

Mix the $0.1 \mathrm{~g}$ petroleum and $50 \mathrm{~mL}$ surfactant solution with different concentration and its compound solution (50:1) into a $100 \mathrm{~mL}$ plug cone bottle and oscillate at a constant temperature oscillator at $25^{\circ} \mathrm{C}$ for $5 \mathrm{~h}$ at a speed of $150 \mathrm{r} / \mathrm{min}$. After the solution was quiesced in the funnel for $2 \mathrm{~h}$, the lower part of the solution was removed for $10 \mathrm{~mL}$. Dichloromethyl chloride was used to extract, with ultraviolet spectrophotometry used to determine the concentration of petroleum in the solution. The solubilization effect is calculated by Eqs.(1), (2), (3) and (4).

\section{Influencing factors of leaching repair}

a. Complex proportion

$2.5 \mathrm{~g}$ oily soil sample containing $5 \%$ oil was put into a $100 \mathrm{~mL}$ plug conical bottle. The compound ratios (SDS: Tw-80) of $4 \mathrm{~g} / \mathrm{L}$ were10: 1, 20: 1, 30: 1, 40: 1, 50: 1, 60: 1.70: 1.80: 1.90: 1 and 100: 1 for $50 \mathrm{~mL}$. The sample was placed on the constant temperature oscillator at $25^{\circ} \mathrm{C}$ for 1 hour at the rate of $150 \mathrm{r} / \mathrm{min}$. After stilling for $10 \mathrm{~min}$, the supernatant was discarded, and the soil was set at $105^{\circ} \mathrm{C}$ for $1 \mathrm{~h}$. After cooling, $2.0 \mathrm{~g}$ was added to $20 \mathrm{~mL}$ dichloromethane, and then put into an ultrasonic cleaner. The temperature was adjusted to $30^{\circ} \mathrm{C}$, with extraction for $15 \mathrm{~min}$. The extractive was poured into $50 \mathrm{~mL}$ centrifugation tube, and the supernatant was collected at 4,000 r/min rotating speed for $5 \mathrm{~min}$. The volume of the supernatant was fixed, with the measured absorbance and the calculated oil removal rate.

b. Surfactant concentration

The concentration of surfactant solution was $0,1,2,3,4,5$ and $6 \mathrm{~g} / \mathrm{L}$, respectively. Other operating conditions were referred to Eq.(1).

c. Leaching temperature

Run the constant temperature oscillator, and adjust the temperature to 10, 20, 25, 30, 40,50 and $60^{\circ} \mathrm{C}$. Other operating conditions refer to Eq.(1).

d. $\mathrm{PH}$ value of the solution

The soil sample containing $5 \%$ oil was put into $100 \mathrm{~mL}$ plug conical bottle, added with surfactant solution. The $\mathrm{pH}$ value of the solution was adjusted to 3, 5, 7, 9 and 11 with sodium hydroxide and hydrochloric acid solution, respectively. Other operating conditions were referred to Eq.(1).

e. Effect of adding inorganic salts

Add different concentrations of sodium chloride, calcium chloride, magnesium chloride, sodium sulfate, sodium bicarbonate, sodium silicate and sodium phosphate surfactant solutions. Other operating conditions refer to Eq.(1). 


\section{Results and discussions}

\section{Method for determination of petroleum in soil}

The UV spectrophotometer was used to select the standard solution of $254 \mathrm{~nm}$ in the wavelength range of 200-400 $\mathrm{nm}$. The standard curve for the experiment is given in Figure 2. The oil removal rate was calculated by Eq.(5). In Figure 3, 284/336 nm is the excitation/emission peak corresponding to light oil, and 256/360 $\mathrm{nm}$ heavy oil corresponding excitation/emission peak.

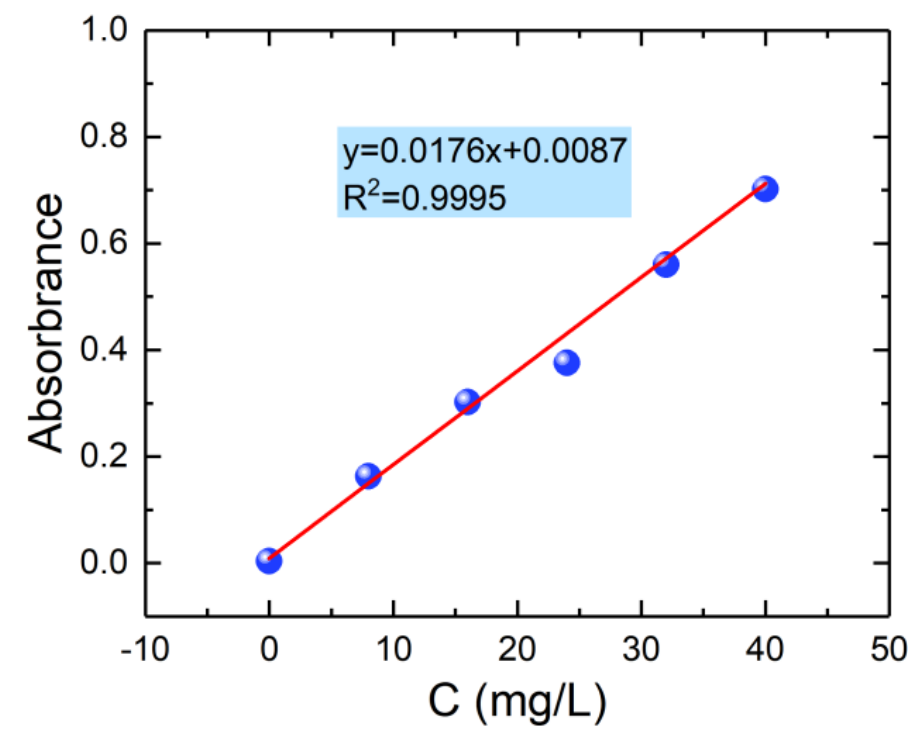

Figure 2. Standard curves for experiments

(a)

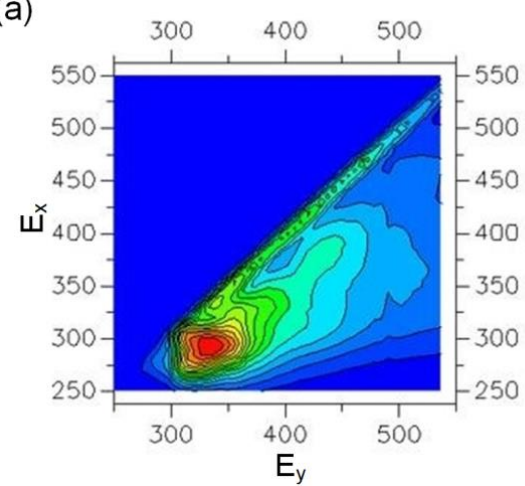

(b)

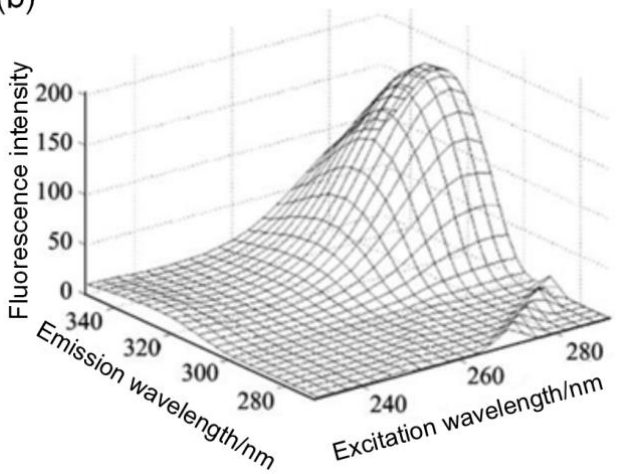

Figure 3. Three-dimensional fluorescence analysis of crude oil

The emission wavelength of $325 \mathrm{~nm}$ is equivalent to a ring, a binary aromatic compound (abbreviated as one, two rings), a $350 \mathrm{~nm}$ equivalent to a binary ring, a tricyclic aromatic light compound (hereinafter referred to as Bicyclic), and a tricyclic aromatic compound (tricyclic) of $375 \mathrm{~nm}$, that equals to the tricyclic aromatic compound (tricyclic) (Lu et al., 2014; Meshram et al., 2017).

The content of heavy oil in crude oil was higher than that of light oil, and the content of tricyclic aromatic hydrocarbon in aromatic hydrocarbon was the highest. Compared 
with crude oil, the light intensity of light oil and aromatics under tricyclic ring decreased significantly in undried soil samples. In the preparation of soil samples, the light oil and aromatic hydrocarbon components under tricyclic ring migrated to the atmosphere due to their natural volatilization. The components of light oil were volatile in the preparation of samples, but the components of heavy oil were not easy to volatilize. Compared with the undried soil samples, the fluorescence intensity of light oil components of contaminated soil samples decreased slightly after drying, while the light burst intensity of heavy oil components decreased obviously. The possible reason was that the light intensity of the heavy oil group was lower than that of non-dried soil samples. Components were converted into volatile substances when dried at high temperatures.

\section{Solubilization test}

Figure 4 shows the solubilization effect of the mixture of two surfactants on petroleum in the selected mass concentration range. According to the literature, the solubilization capacity of Tw-80 is higher than that of SDS, and the solubilization effect of the compound surfactant is close to that of SDS (Shi et al., 2013; Enright et al., 2017).

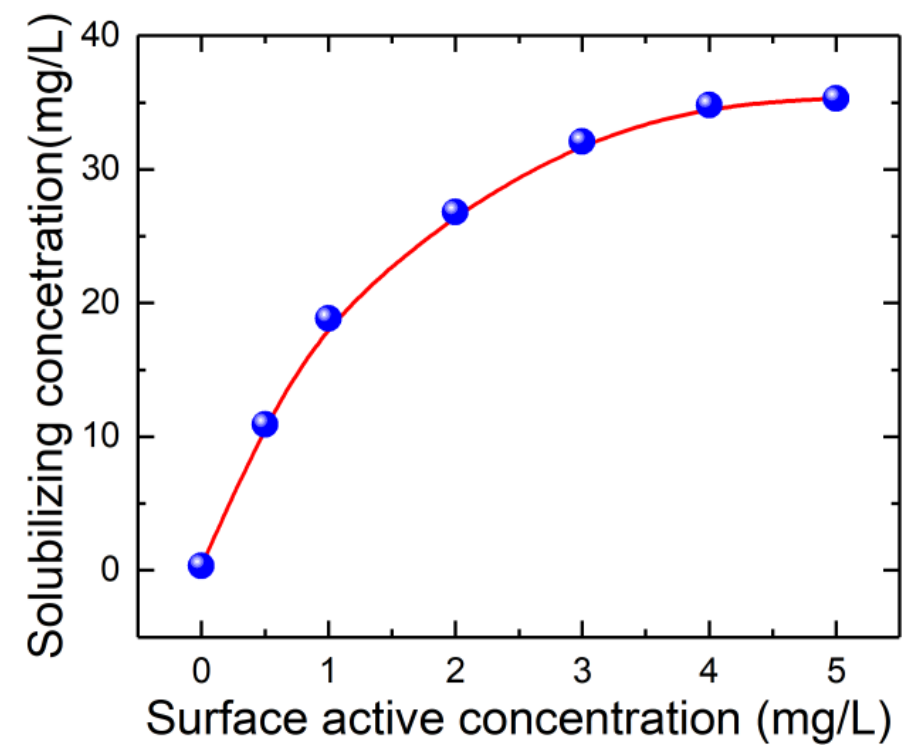

Figure 4. Solubilization curve of SDS/Tw-80 after blending

However, the amount of SDS used is reduced by one time, indicating that the complex surfactant can improve the solubilization of the surfactant to solubilize petroleum. Therefore, the compound surfactant is used to carry on the petroleum elution experiment.

\section{Factors affecting leaching repair}

\section{Compound proportion}

Figure 5 shows the effect of complex ratio on the removal of petroleum from surfactant solution. It is evident that as the ratio of SDS and Tw-80 increases, the effect of the ratio of the compound on the oil removal rate increases first and then becomes 
smaller. This is because the interaction between the two compounds can be found when the ratio is around 50, and the effect of the compound ratio on the decreasing rate is the highest. According to Figure 6, when the ratio of SDS and Tw-80 is 50-60, the oil removal rate reaches the maximum. The anion surfactant SDS is electronegative in the solution, not easy to be adsorbed by the soil. While the Nonionic surfactant Tw- 80 is not ionized in the solution, it is electro neutral, easy to be adsorbed by the soil with negative charge.

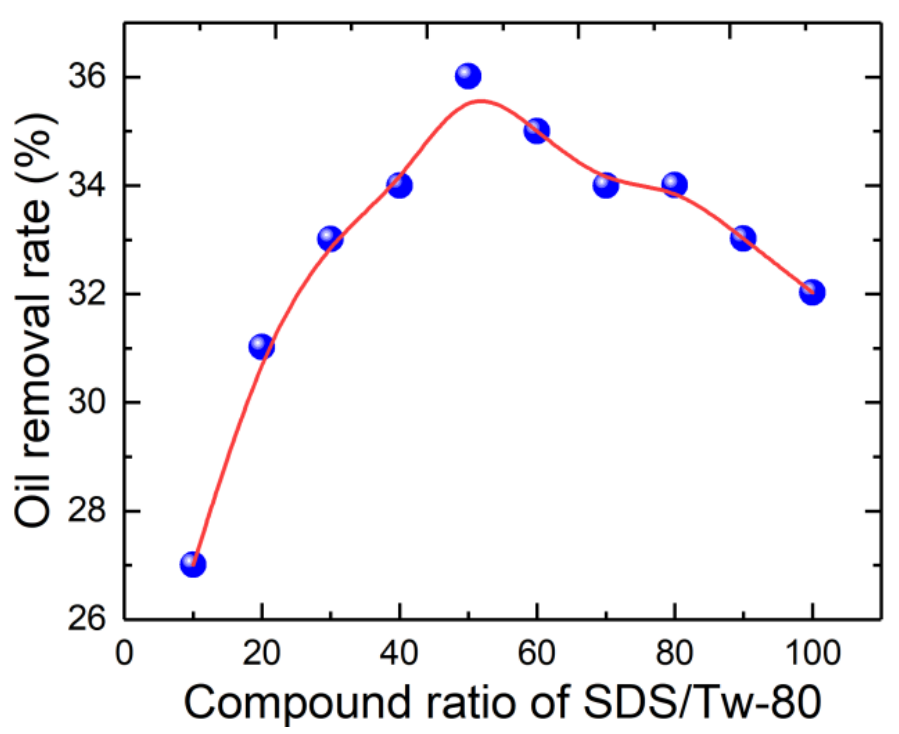

Figure 5. Effect of compound proportion on oil Removal rate

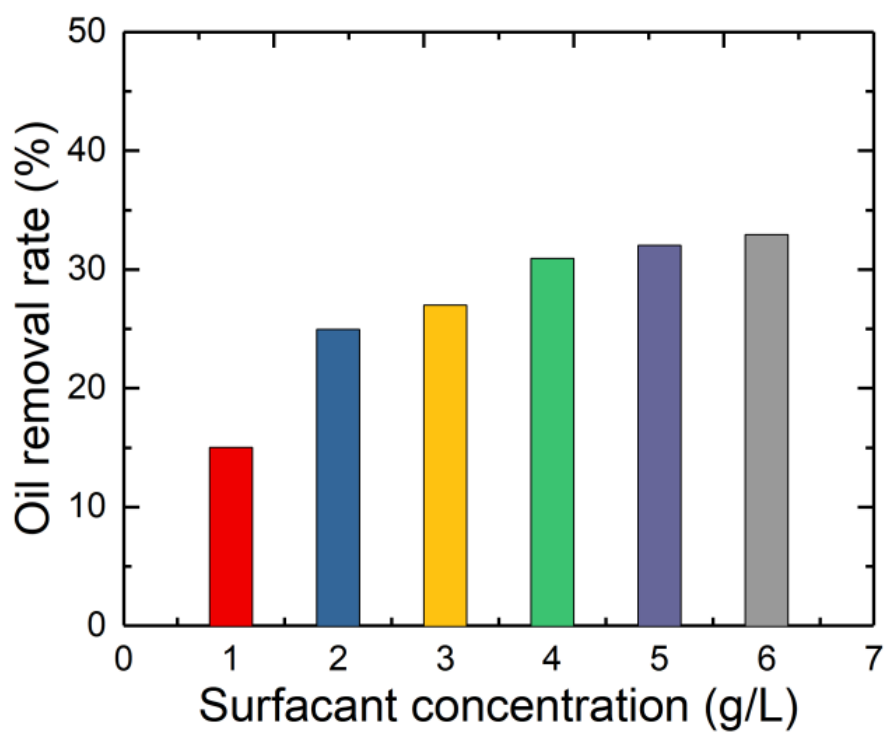

Figure 6. Effect of surfactant concentration on oil Removal rate

With the SDS, the weak intermolecular interaction of Tw-80 is replaced by the interaction between hydrophilic ion dipoles to form mixed micelles (Carbone et al., 2013), which can reduce the soil adsorption, ensure the effective mass concentration 
and improve the oil removal rate. Besides, for nonionic surface activity in complex surfactants, the larger proportion of the surfactant means the smaller CMC and the higher removal rate (Elazhari-Ali et al., 2013). Moreover, the CMC (2.5 g/L) of SDS is much larger than that of Tw-80 $(0.013 \mathrm{~g} / \mathrm{L})$. The increased ratio of SDS to surfactant increases the critical micelle concentration of surfactant, which leads to the decrease of oil removal rate inthe same concentration. The compound ratio of SDS/Tw-80 selected in the experiment was 50:1.

\section{Surfactant concentration}

Figure 6 shows the effect of surfactant concentration on oil removal by elution. With the increased surfactant concentration, the oil removal rate increases. When the removal rate is larger than $4 \mathrm{~g} / \mathrm{L}$, the removal rate of the easily desorbed oil component in the soil will be washed down, and the removal rate will no longer increase (Gros et al., 2014). Excessive use can lead to a waste of chemicals and secondary soil pollution. Therefore, the optimum concentration of surfactant for remediation of contaminated soil should be considered based on the economy and environmental protection. The concentration selected in the experiment was $4 \mathrm{~g} / \mathrm{L}$.

\section{Leaching temperature}

Based on Figure 7, we speculate that the temperature has a significant effect on the oil removal rate and the removal rate increases with the increase of temperature. High temperature has following advantages: enhancing the fluidity of oil, weakening the adhesion force of soil, providing the energy needed for desorption, and promoting desorption of oil.

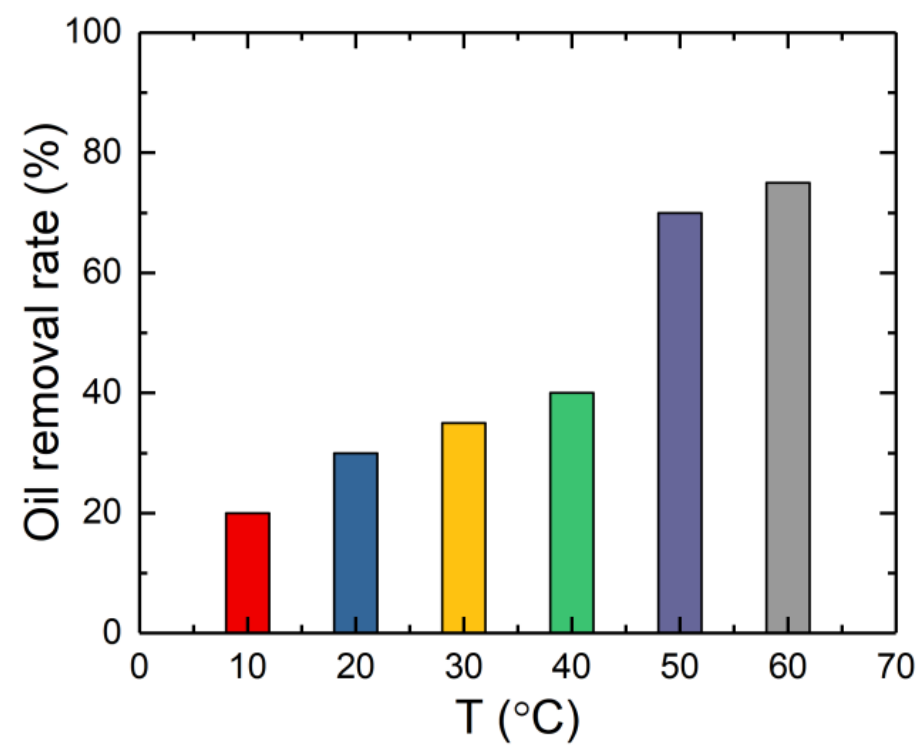

Figure 7. Effect of leaching temperature on oil Removal rate

The increase of temperature prevents the adsorption of Tw-80, and the increased solubility of SDS by soil is beneficial to the formation of micelles. However, if the temperature is too high, the surface activity and solubility of nonionic surfactants will 
be decreased, with the reduced oil removal rate. With the high temperature, the energy consumption increases, so the appropriate temperature should be chosen according to the repair concrete condition. The work studied the remediation of petroleum contaminated soil by surfactant at room temperature, with the experimental temperature of $25^{\circ} \mathrm{C}$.

\section{Solution $\mathrm{pH}$}

Figure 8 shows the effect of $\mathrm{pH}$ value on the removal of petroleum by surfactant solution leaching. The removal rate of petroleum increases with the increased $\mathrm{pH}$ value. The increase of the alkalinity of solution leads to the increased negative charge of the soil particles, the increased repulsion between surfactant molecules and the soil, and the decreased adsorption of the soil. In addition, the alkaline substance in surfactant solution can react with the acid substance in petroleum to form salts, which increases the water solubility of petroleum. Some components have certain surface activity, which can improve the removal rate of petroleum. Furthermore, the increase of $\mathrm{pH}$ in surfactant solution reduces the interfacial tension.

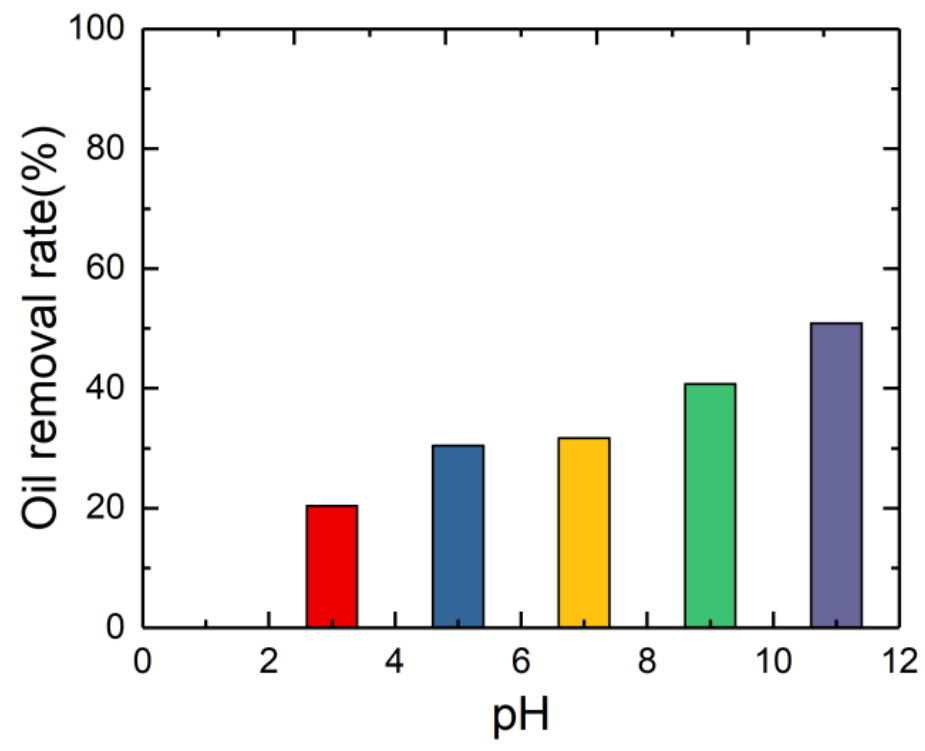

Figure 8. Effect of $\mathrm{PH}$ value of solution on oil deoiling rate(PH is hydrogen ion concentration)

\section{Effect of adding inorganic salts}

Figures 9 and 10 indicate the effect of inorganic salts on the removal of petroleum from surfactant solution. Figure 9 shows that with the increase of concentration, sodium chloride, Korea chloride (In the field of inorganic chemistry, it is a salt compound formed by the combination of a negatively charged chloride ion and a positively charged cation of another element.) and magnesium chloride reduce the oil removal rate. Figure 10 shows the oil removal rate is increased by sodium sulfate, sodium bicarbonate, sodium cinnamate and sodium phosphate.

SDS ionizes in the water can produce CI2H25O-SO3-, energy and $\mathrm{Ca}^{2+}, \mathrm{Mg}^{2+}$ and form precipitation. Sodium ion produced by sodium chloride ionization can increase the diffusion double layer of the ionic micelle and improve the activity of surfactant. However, it exchanges calcium ion from the soil, reducing the effective active 
substances of SDS and destroying the compound system. The addition of calcium chloride and magnesium chloride not only leads to the formation of precipitation of SDS directly, but also interacts with soil, block the void of soil and hinder the transfer of oil to surfactant solution. Although sodium sulfate brings a large number of sodium ions, but sulfate provides a lot of negative charges, and reduces the adsorption of surfactant, surface tension of surfactant solution and interfacial tension between oil and water.

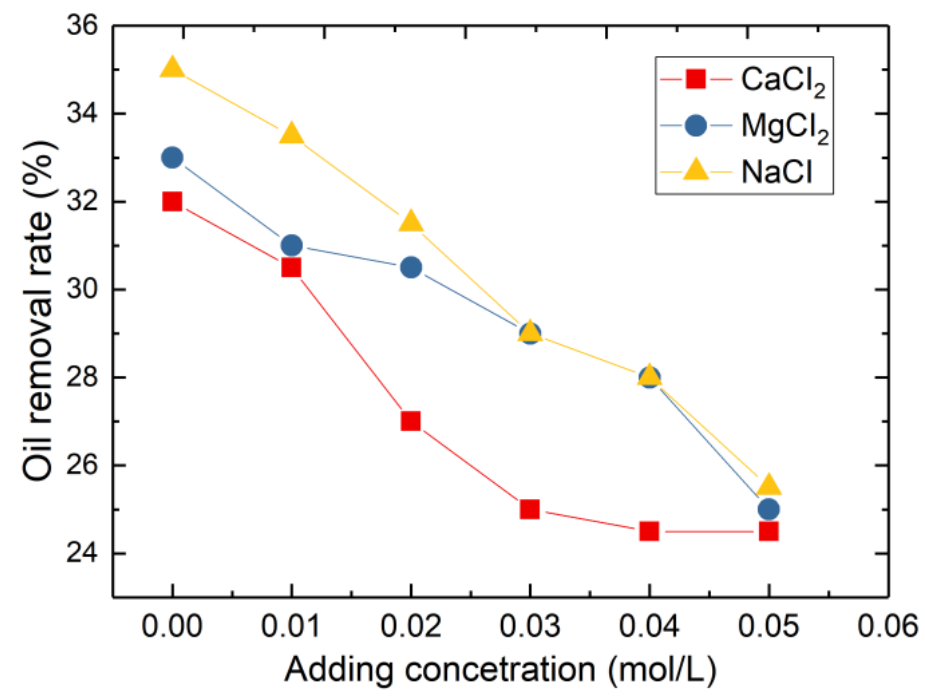

Figure 9. Effect of adding inorganic salts such as sodium chloride, calcium chloride and magnesium chloride on oil deoiling rate

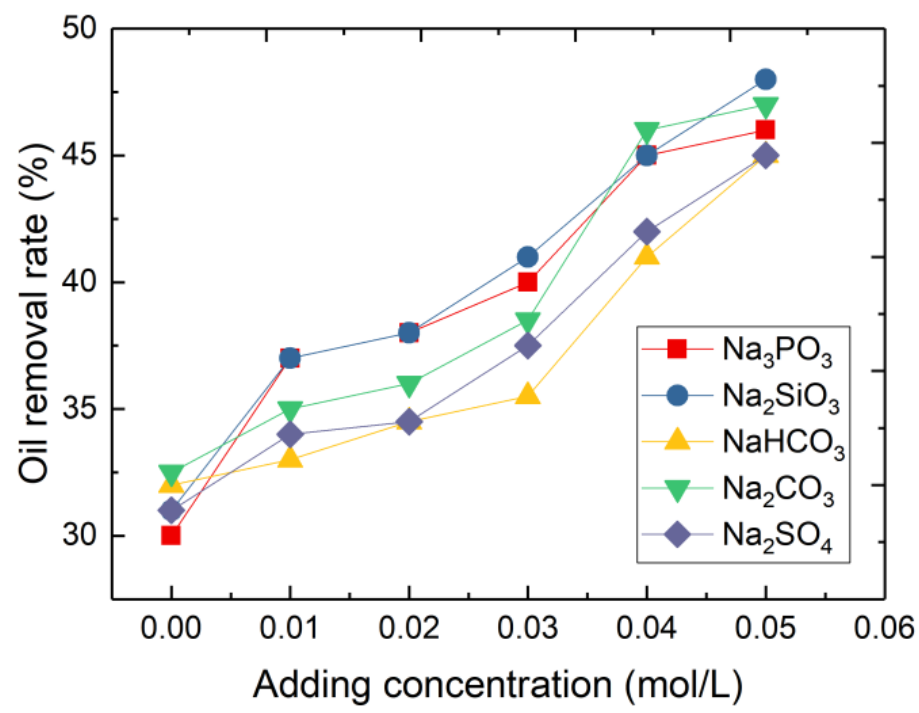

Figure 10. Effect of adding inorganic salts such as sodium sulfate, sodium bicarbonate, sodium silicate and sodium phosphate on oil deoiling rate

Finally, the solubilization of surfactants is improved. Sodium carbonate, sodium bicarbonate, sodium WaaS and sodium phosphate are all strong alkali and weak acid 
salts. Hydrolysis makes surfactant solution alkaline, which is beneficial to the removal rate of petroleum. The cation produced by ionization of three inorganic salts can precipitate with the continuous ion in the solution and reduce the negative effect of the hardness ion. In addition, sodium silicate and its hydrolysate can be adsorbed on the surface of soil particles to form a protective film, thus preventing the desorbed oil from being adsorbed again by the soil. Although the above inorganic salts can bring about the precipitation effect of sodium ions, the positive effects of these inorganic salts on the improvement of removal rate are more evident than these adverse effects. On the whole, these inorganic salts play an essential role in promoting oil elution.

According to the above figures, the results of the solidified oil-containing soil and the directly solidified product leachate are quite different. A series of surfactants and composite surfactants were used to determine the oil solubilisation and single factor experiments to determine the surfactant elution. The results showed that the anionicnonionic surfactant was used to elute oil-contaminated soil. The method is better than the previous method and has superior performance. It can provide some technical support for surfactant elution and oil-contaminated soil.

\section{Conclusions}

Based on the ecological protection, the work discussed the method of petroleum hydrocarbon pollution leaching in farming land, and used the ex-situ leaching for soil remediation. In terms of the solubilization, a series of comparative experiments were established to analyse the effects of concentration and ratio of surfactant concentration as well as the addition of additives on the leaching. The following conclusions are obtained.

a. The oil solubilization of Tw- 80 was higher than that of SDS. The removal rate of SDS/Tw-80 complex surfactant solution increased first and then decreased with the increase of SDS ratio. The maximum value was obtained when the compound ratio ranged from 50 to 60 . From the oil elution effect, economy and benefit to experiment, $1 \mathrm{~h}$ was selected as the oscillation time.

b. The higher the surfactant concentration was, the higher the oil removal rate was. When the surfactant concentration was higher than $4 \mathrm{~g} / \mathrm{L}$, the oil removal rate increased slowly. In the range of 10 to $60^{\circ} \mathrm{C}$, the temperature had a significant effect on the removal rate of petroleum in contaminated soil. The removal rate increased with the increase of temperature. The high temperature was beneficial to the removal of polycyclic aromatic hydrocarbons (PAHs). Alkaline environment was good for the removal of petroleum, heavy oil components and tricyclic aromatic compounds.

c. The addition of inorganic salts affected the oil elution with surfactants. Sodium chloride, calcium chloride and magnesium chloride reduced the removal rate of oil, while sodium sulfate and sodium bicarbonate reduced the removal efficiency of oil eluted by sodium chloride, calcium chloride and magnesium chloride. Sodium silicate and sodium phosphate increased the removal rate of oil eluted.

d. According to experimental results, it can be concluded that the anion-nonionic surfactant proposed in this paper is better than the previous method, and can provide better technical support for surfactant elution and oil-contaminated soil. 


\section{REFERENCES}

[1] Akinlua, A., Jochmann, M. A., Schmidt, T. C. (2015): Ionic Liquid as Green Solvent for Leaching of Polycyclic Aromatic Hydrocarbons from Petroleum Source Rock. Industrial \& Engineering Chemistry Research 54(51): 12960-12965.

[2] Arauzo, M., Martínez-Bastida, J. J. (2015): Environmental factors affecting diffuse nitrate pollution in the major aquifers of central Spain: groundwater vulnerability vs. groundwater pollution. - Environmental Earth Sciences 73(12): 1-16.

[3] Arauzo, M., Valladolid, M. (2015): Drainage and N-leaching in alluvial soils under agricultural land uses: Implications for the implementation of the EU Nitrates Directive. Agriculture Ecosystems \& Environment 179(5): 94-107.

[4] Åslund, M. W., Stephenson, G. L. (2013): Comparison of earthworm responses to petroleum hydrocarbon exposure in aged field contaminated soil using traditional ecotoxicity endpoints and (1) H NMR-based metabolomics. - Environmental Pollution 182: 263-268.

[5] Brown, D. M., Okoro, S., Van, G. J. (2017): Comparison of landfarming amendments to improve bioremediation of petroleum hydrocarbons in Niger Delta soils. - Science of the Total Environment 596-597: 284-292.

[6] Carbone, C., Dinelli, E., Marescotti, P. (2013): The role of AMD secondary minerals in controlling environmental pollution: Indications from bulk leaching tests. - Journal of Geochemical Exploration 132(3): 188-200.

[7] Dong, W., Lin, X., Du, S. (2015): Risk assessment of organic contamination in shallow groundwater around a leaching landfill site in Kaifeng, China. - Environmental Earth Sciences 74(3): 2749-2756.

[8] Elazhari-Ali, A., Singh, A. K., Davenport, R. J. (2013): Biofuel components change the ecology of bacterial volatile petroleum hydrocarbon degradation in aerobic sandy soil. Environmental Pollution 173(1): 125-132.

[9] Enright, E. F., Joyce, S. A., Gahan, C. G. M. (2017): Impact of Gut Microbiota-Mediated Bile Acid Metabolism on the Solubilization Capacity of Bile Salt Micelles and Drug Solubility. - Mol Pharm 14(4): 1251-1263.

[10] Fallah, M., Shabanpor, M., Ebrahimi, S. (2015): Evaluation of petroleum impacts on some properties of loamy sand soil with the main focus on hydraulic properties. Environmental Earth Sciences 74(6): 4751-4762.

[11] Gao, S. S., Xu, P., Zhou, F. (2016): Quantifying nitrogen leaching response to fertilizer additions in China's cropland. - Environmental Pollution 211(211): 241-251.

[12] Gros, J., Reddy, C. M., Aeppli, C. (2014): Resolving biodegradation patterns of persistent saturated hydrocarbons in weathered oil samples from the Deepwater Horizon disaster. Environmental Science \& Technology 48(3): 1628-1637.

[13] Janajreh, I., Alshehi, A. (2018): Anaerobic co-digestion of petroleum hydrocarbon waste and wastewater treatment sludge. - International Journal of Hydrogen Energy: 1-12.

[14] Jha, S. K., Ahmad, Z., Crowley, D. E. (2018): Fuzzy-genetic approaches for estimation of microbial rock phosphate solubilization in sandy clay loam textured soil. - Computers \& Electronics in Agriculture 150: 125-133.

[15] Kim, J., Lee, A. H., Chang, W. (2017): Enhanced bioremediation of nutrient-amended, petroleum hydrocarbon-contaminated soils over a cold-climate winter: The rate and extent of hydrocarbon biodegradation and microbial response in a pilot-scale biopile subjected to natural seasonal freeze-thaw temperatures. - Science of the Total Environment 612: 903-910.

[16] Li, X., Wang, X., Zhang, Y. (2014): Extended petroleum hydrocarbon bioremediation in saline soil using Pt-free multianodes microbial fuel cells. - Rsc Advances 4(104): 5980359808.

[17] Li, J., Jia, C., Ying, L. (2015): Multivariate analysis of heavy metal leaching from urban soils following simulated acid rain. - Microchemical Journal 122(9): 89-95. 
[18] Lu, L., Huggins, T., Jin, S. (2014): Microbial metabolism and community structure in response to bioelectrochemically enhanced remediation of petroleum hydrocarboncontaminated soil. - Environmental Science \& Technology48(7): 4021-4026.

[19] Ma, J., Deng, Y., Yuan, T., Zhou, J., Alvarez, P. J. J. (2015): Succession of microbial functional communities in response to a pilot-scale ethanol-blended fuel release throughout the plume life cycle. - Environmental Pollution 198: 154-160.

[20] Mauko, A. P., Oprčkal, P., Mladenovič, A. (2018): Comparative Life Cycle Assessment of possible methods for the treatment of contaminated soil at an environmentally degraded site. - Journal of Environmental Management 218: 497-508.

[21] Meshram, P., Pandey, B. D., Mankhand, T. R. (2014): Extraction of lithium from primary and secondary sources by pre-treatment, leaching and separation: A comprehensive review. - Hydrometallurgy 150: 192-208.

[22] Mortazavi, B., Horel, A., Beazley, M. J. (2013): Intrinsic rates of petroleum hydrocarbon biodegradation in Gulf of Mexico intertidal sandy sediments and its enhancement by organic substrates. - Journal of Hazardous Materials 244-245(2): 537-544.

[23] Mota, I. D. O. D., Castro, J. A. D., Rui, D. G. C. (2015): Study of electroflotation method for treatment of wastewater from washing soil contaminated by heavy metals. - Journal of Materials Research \& Technology 4(2): 109-113.

[24] Shi, Z., Chen, J., Yin, X. (2013): Effect of anionic-nonionic-mixed surfactant micelles on solubilization of PAHs. - J Air Waste Manag Assoc 63(6): 694-701.

[25] Yang, X., Yuan, X., Zhang, A. (2015): Spatial distribution and sources of heavy metals and petroleum hydrocarbon in the sand flats of Shuangtaizi Estuary, Bohai Sea of China. - Marine Pollution Bulletin 95(1): 503-512. 